\title{
Enabling Early Career Sustainability Researchers to Conduct Transdisciplinary Research: Insights from Austria
}

\author{
Oliver Gerald Schrot ${ }^{1 *}$, Hanna Krimm ${ }^{2}$ and Thomas Schinko ${ }^{3}$ \\ ${ }^{1}$ Faculty of Geo- and Atmospheric Sciences, Institute of Geography, University of Innsbruck, Innsbruck, Austria \\ 2 alpS GmbH, Innsbruck, Austria \\ ${ }^{3}$ Risk and Resilience Program, International Institute for Applied Systems Analysis, Laxenburg, Austria \\ * Corresponding author: oliver.schrot@uibk.ac.at; Tel.: +43 69910786208
}

Submitted: 17 March 2020 | In revised form: 23 July 2020 | Accepted: 5 August 2020 |

Published: 19 October 2020

\begin{abstract}
Human influences on Earth's natural systems are accelerating, with anthropogenic climate and global change posing existential risks for mankind. To overcome the policy implementation gap in practice both collective and transformative actions for sustainability involving science, policy and society are urgently needed. In the realms of science, this relates to taking inter-and transdisciplinary research approaches to foster exchange and co-designing policy options between researcher, decision-makers and other societal stakeholders; however, such collaboration is often limited by time, funding and complexity constrains.
\end{abstract}

This paper recognises that particularly early career climate change and sustainability researchers are exposed to both the claim for and practical challenges of inter- and transdisciplinarity. For a first qualitative investigation of Austrian early career researchers' preparedness for conducting participatory research with societal stakeholders, this study examines perspectives of twelve early career researchers participating in a young scientists' workshop.

Using a pre-post survey and analysing data by content, our findings indicate that workshop participants have to manage stakeholder processes directly after graduation and, due to a lack of methodological training, only use a small fraction of existing social science methods and participatory settings for stakeholder collaboration. To support other early career researchers and future students in Austria in developing strong inter-and transdisciplinary research skills, we highlight the added-value of integrating hands-on workshops with societal stakeholders, regular exchange of lessons learned and transdisciplinary lectures into university education. Offering more practice-oriented transdisciplinary learning activities during undergraduate education, like excursions and mini-projects in which students can develop and train participatory methods together with stakeholders under guidance, is believed to be a fruitful strategy in this context.

Keywords: climate change; early career; interdisciplinarity; research practice; stakeholders; sustainability; transdisciplinarity 


\section{Introduction}

In 2020, human interference with the Earth's environmental systems has reached a magnitude that is unprecedented in history [1], pushing the world into an alarming trajectory at the same time [2]. Compared to pre-industrial times, humans' intensified use of fossil fuels and large-scale changes in global land use have caused approximately $1.0^{\circ} \mathrm{C}$ of global warming, triggering climate-related impacts and risks that dangerously influence livelihoods on all continents $[3,4]$. Moreover, unsustainable consumption and other drivers turn out to endanger the planet's biosphere. For example, plastic is found to pollute the Pacific Ocean [5], and ongoing land-use changes could transform protected areas and ecosystems [6].

Overcoming such grand environmental risks whilst avoiding substantial harm on human populations requires taking prompt and collective action to stabilize the Earth's environmental systems and to guide societies towards sustainable development pathways [7]. This and the ever-increasing urgency of enhanced actions towards sustainability are probably best exemplified by the United Nations' 17 Sustainable Development Goals (SDGs) framework [8] and the Sendai Framework for Disaster Risk Reduction 2015-2030 [9]. Other examples are the climate goals formulated by the 2015 Paris Agreement [10] and derived regional and national climate mitigation and adaptation plans.

\subsection{Participatory Research for Closing the Science-Policy-Implementation Gap}

Despite progress on environmental and climate policies that has been made in the last three to four decades, there remain apparently unbridgeable gaps between knowledge, awareness and action for sustainability. For example, scientific evidence on anthropogenic climate change did so far not translate into sufficient societal actions in line with the Paris Agreement [11]. Due to complexity and interconnectedness many risks of global environmental change are poorly understood and traditional research has been fond not effective enough in taking the perceptions of societal actors into perspective [12]. To overcome this limitation to scientific knowledge production, inter- and transdisciplinary approaches set out to cross disciplinary boundaries, whilst taking problem-driven approaches is believed leading to increased collaboration with societal stakeholders [13,14]. Linking academic knowledge with real-life actions should result in more robust and socially accepted research outcomes [15]. Specifically, the transdisciplinarity paradigm follows this notion and aims at engaging with the hidden social complexities of modern environmental problems [16,17]. It is one objective of transdisciplinarity to evoke social learning for sustainability [18-20]; however, the societal outcomes of participatory research with stakeholders strongly depends on researchers' understanding of and competences for civic engagement. Prominent stumbling-blocks for example are researchers' poorly developed abilities to take multifaceted approaches and their skills in mediating between diverging epistemological positions [21].

Challenges to collaboration with stakeholders across a spectrum from getting societal insights, preferences and opinions all the way to longer-term involvement in experimentation (e.g. urban living labs) also could arise from language differences [22]. Moreover, science-society collaborations require researchers to be experienced in managing group processes. Transdisciplinary endeavours for sustainability are further complicated by uncertainty about the future [23], conflicting expectations between stakeholders and researchers [24], issues related to scientific credibility and impact evaluation $[25,26]$. The manifold practical challenges to successful stakeholder involvement suggest that better preparing present and future scholars for interand transdisciplinarity should be of uttermost importance for the scientific community.

\subsection{The Role of Early Career Researchers in Inter-and Transdisciplinary Climate Change and Sustainability Research}

In this paper, we focus on early career climate change and sustainability researchers (including early professionals) and their previous and ongoing education on transdisciplinary stakeholder involvement. We also study their practical experiences when collaborating with stakeholders in research practice across the continuum from collecting societal insights to the involvement in real-world experiments. A qualitative case study approach is employed, focusing on Austrian Universities, to derive firsthand empirical insights from early career researchers. It is widely assumed that young PhD or post-doc researchers in the fields of climate change and sustainability science in Austria have received undergraduate education, respectively training that qualifies them for conducting participatory research with stakeholders. Such education is likely to have equipped them with a distinctive inter-and transdisciplinary identity that also is motivating them for solving grand environmental challenges $[27,28]$. However, reality looks different due to the following obstacles early career researchers are facing. Young researchers' perspectives of as well as their early experiences with transdisciplinary research could have been disadvantaged by the characteristics of modern academic environments itself. The latter has been recognized by previous studies outside the context for Austria, which all imply a lack of investment in early career researchers' institutional environments, and their competences for conducting inter-and transdisciplinary research; For example, it is unequivocal that today's preand post-doc students are facing a more competitive situation than their senior colleagues did 20-30 years ago [29]. And, publication pressure is real, especially at early-career stages. At the same time, transdisciplinary research with stakeholders is increasingly demanded by funders; a contradictory situation, since research involving stakeholders often translates into more project coordination efforts and 
less time for working on scientific publications [30]. Doctoral students at the beginning of their academic careers sometimes lack the necessary training and experience in conducting transdisciplinary research, which may result in inadequately designed stakeholder processes [31]. Moreover, transdisciplinary researchers are also confronted with a less developed (compared to more established sciences) yet steadily growing transdisciplinary academic publication culture $[20,32]$. This disciplinary publishing bias might explain why even some doctoral students themselves rate inter-and transdisciplinary research as less rigorous than disciplinary research [33].

Early career climate change and sustainability research also is found to be impeded by disciplinary doctoral programs offering little space for strengthening team-science skills, or the development of skills to balance knowledge from science with knowledge from society [34]. As a matter of fact, such disciplinary graduate programs cannot be effective in deepening learners' skills for transdisciplinary research [35]. In addition, young researchers in disciplinary doctoral programs may lack senior guidance in identifying and writing for transdisciplinary journals. Previous research also showed that an increasing share of early career researchers who have received training in interdisciplinary master's programs are challenged by mediating different epistemologies, developing a rich methodological skill-set and implementing participatory approaches at the same time. In other words, early-career practice in transdisciplinary research is influenced by the dichotomy between high academic standards and the often-proclaimed need for co-production of knowledge with stakeholders [31],

Against this background, improved education on interand transdisciplinarity is widely perceived as a general strategy to build early career researchers' conceptual and practical skills for stakeholder involvement. For example, learning in peer-groups in which common experiences are shared could help early career researchers to reach higher levels of reflection before, during and after inter-and transdisciplinary projects [36]. Furthermore, such learning could prepare them for avoiding practical stumbling blocks that arise during stakeholder involvement [37].

\subsection{Research Questions and Contributions to the Literature}

Previous studies, undertaken in other geographical contexts than Austria, have investigated climate change and sustainability researchers' perspectives of and experiences with the paradigms of inter-and transdisciplinarity. The papers from Killion et al. [31], Hein et al. [33], Moore et al. [34], Rivera-Ferre et al. [35], Haider et al. [27] and Jaeger-Erben et al. [28] are illustrative examples of such explorative research efforts. Most of these studies derived suggestions for improving non-curricular learning opportunities, career paths, mentorship as well as doctoral training programmes for early career researchers. Suggestions were based on survey data and collective workshop reflections. However, none of these previous studies has explicitly taken a look back into the preceding bachelor's or master's programmes of current doctoral or post-doc candidates. What is thus missing in the existing literature are in-depth, first-hand insights into early career researchers' levels of knowledge about stakeholder involvement that has been gained during their undergraduate education. And, whether such educational experiences sufficiently prepared them for conducting participatory research with stakeholders in their ongoing $\mathrm{PhD}$ or post-doc research. What is also missing in the existing literature are peer-group reflections about potential improvements to inter- and transdisciplinary undergraduate education, since previous studies focused on research training during graduate years. Many doctoral candidates start involving stakeholders in their doctoral research projects right after their master's education. We therefore hypothesize that next to graduate research training, improving undergraduate education on inter-and transdisciplinary research skills will be a particularly important leverage point for better preparing upcoming researchers for science together with societal stakeholders [38].

Addressing this gap in the peer-reviewed literature and by focussing on early career researchers' experiences with inter- and transdisciplinary education and research, collected at a workshop in Vienna, this paper adds further empirical insights on inter-and transdisciplinary climate change and sustainability research practice in Austria [36]. Drawing from workshop participants' reflections, this paper further aims at developing general recommendations for the Austrian higher education system to better prepare the next generation of climate change and sustainability researchers for stakeholder involvement. Our geographical focus is Austria; however, we think that our general findings are also useful for university teachers in other geographical contexts. The following three central research questions were addressed by the reflective two-day workshop for young scientists and will be answered in the remainder of this paper:

1. Based on their academic backgrounds, what do early career researchers in Austria know about theory and practice of inter-and transdisciplinarity?

2. What are early career researchers' practical experiences when collaborating with stakeholders during their $\mathrm{PhD}$ or post-doc research projects?

3. What did they learn about stakeholder involvement during the workshop and what recommendations for improving inter-and transdisciplinary science education at Austrian Universities were identified by workshop participants?

\section{Background on the Austrian Early Career Researchers' Workshop}

The Science Plan for climate research in Austria was realized in March 2018 and adopts an inter- and transdisciplinary research rationale. Initiated by the former Federal Ministry of Science and Research and further developed by the Climate Change Centre Austria (CCCA), it represents a five-to- 
seven-year research strategy for recent climate change and sustainability science for Austrian research institutions. The document leaves no doubt that barriers and opportunities inherent to mitigation, adaptation and sustainability transformations demand climate and sustainability researchers to open-up their knowledge systems and to develop awareness for the social relevance of their academic work. The corresponding message of the Science Plan to address important societal issues more effectively is as follows:

'Global change in general and climate change in particular pose major scientific challenges... In order to tackle the subsequent challenges, research of individual science disciplines must be complemented by applying inter- and transdisciplinary approaches... Stakeholders should therefore be involved in the research process from an early stage onward (co-design, co-production, co-exploration)' ([39], p. 3-4).

The academic culture leading to this message is supposed to address senior researchers but is also believed to have influenced early career climate change and sustainability researchers at Austrian universities, including young professional who are working in related contexts as well. In April 2018, therefore the idea was born to give young climate change and sustainability researchers in Austria their own platform for sharing discussions on inter- and transdisciplinary research, for collective reflections about stakeholder involvement and for the eventual aim of codesigning joint research projects. To realise this idea, the first annual workshop for young climate change and sustainability researchers (including professionals) took place on November 18-19, 2018 in Vienna (see Figure 1). Under the headline 'Participatory Approaches in Climate Change and Sustainability Research: Sharing Experiences, Best Practices and Stumbling Blocks', the CCCA invited early career researchers and professionals (i.e. who were mainly pre-doc students and some post-docs) from all Austrian universities to apply for it. Participants were selected based on short e-mails stating their motivation for joining the workshop, their research background and a short curriculum vitae. Overall, sixteen early career climate change and sustainability researchers at $\mathrm{PhD}$ or postdoc level applied for the workshop but only fourteen were invited. Two applicants were not invited because they were Master students not doing research themselves and therefore did not meet the criteria for participation. The workshop started by improving participants' understanding of participatory approaches and practical collaboration with stakeholders. For this purpose, a lecture that included several case studies was given by a senior scientist working in the field of disaster risk reduction and participatory stakeholder processes. The workshop also aimed at creating reflexive space for deliberative dialogue among and mutual learning between participants [40]. To stimulate discussions and exchange of early-career experiences, a round-table format was applied to invite workshop participants to share their perceived stumbling blocks and best practices when dealing with stakeholder involvement in their current research practice [41]. During reflection phases, workshop participants reflected about the above-mentioned content and discussed their research projects of which all included stakeholders. Furthermore, they came up with several recommendations for improving higher education on inter- and transdisciplinary research in Austria.

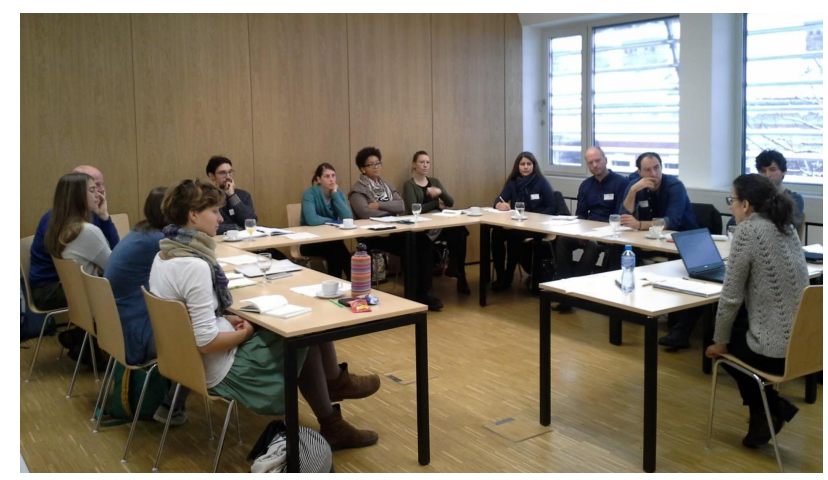

Figure 1. Workshop participants listening to a lecture given by a senior researcher.

\section{Methodology, Data and Qualitative Analysis}

Our basic methodological approach is a single case-study built around the above-mentioned early-career researchers' workshop. This methodological approach was selected for two main reasons. Firstly, as a qualitative methodology a single-case study justifies an in-depth exploration of complex cases that cannot be sufficiently investigated by quantitative analysis since a well-structured sample would be needed [42]. We faced major limitations to sampling in our case, because there is no reliable meta-information about the target population of early-career climate change and sustainability researchers in Austria. University websites alone are often not sufficient to consistently receive contact details of internal and external PhDs belonging to a certain research institute and it is unclear which scientific disciplines are conducting climate change and sustainability science in Austria. Secondly, an explorative single casestudy for Austria seems justified since, to our knowledge, there are no previous empirical studies focussing on Austrian early career researchers' perspectives on inter-and transdisciplinarity. A single-case study therefore could be an opportunity to gain first-hand and in-depth insights from the workshop participants on their educational and practical experiences with inter-and transdisciplinary knowledge production in Austria. We further evaluate whether the workshop provides an authentic learning environment to cultivate self-reflexivity among workshop participants. And, we derive recommendations for improving Austrian transdisciplinary university education [21].

For data collection during and after the early career workshop, this study employed a pre-and post-test design. At the beginning of the workshop, thirteen participants were invited to respond to an ex-ante paper survey (one person did not participate in the workshop even though he/she 
was invited) of which twelve filled out the survey. All items included in the paper survey were open-ended questions, which should have given respondents the opportunity to examine their perspectives and their experiences. The exante survey aimed at collecting background information on workshop participants' educational experiences and their motives for seeking participatory settings with stakeholders during their PhD and post-docs research. Moreover, the survey yielded early career researchers' experiences and perspectives of best practices and common stumbling blocks when collaborating with stakeholders. Early career researchers also were asked to come up with some of their very own recommendations that could be undertaken after the workshop to improve participatory research training and higher education for inter-and transdisciplinary in Austria (see Table 1). To be able to complement the results of the ex-ante survey with direct observations, the authors documented collective reflections among workshop participants using flip charts and field notes.

Within a week after the workshop, an online postworkshop survey was sent out to collect participants' judgements of the effectiveness of the workshop. The postworkshop survey addressed participants' self-assessments whether the collective reflection has been useful to improve personal knowledge regarding participatory approaches, and focussed on the workshops' effectiveness in resolving (some) stumbling blocks related to stakeholder involvement (see Table 2).

Both the data from the ex-ante and ex-post survey as well as data from collected reflections during the workshop were qualitatively analysed using thematic content analysis. Content analysis started by reading through workshop participants' written answers, and then two authors independently coded the data from the survey into text-based categories. Those categories should reflect early career researchers' perspective and experiences and were qualitatively compared after the coding procedure for inter-coder agreement. During the content analysis, the following steps were taken be each coder: (a) obtaining immersion with the written data (i.e. each author familiarised himself/herself with the data set by reading through the text), (b) identifying main meaning units in the original data (i.e. each author extracted thematic paragraphs that were common to most responses, (c) contrasting groups of similar responses, and (d) choosing text-based reference examples from the dataset [43].

Table 1. Survey themes and items of the paper-based ex-ante survey.

\begin{tabular}{|c|c|}
\hline Survey themes & Items (all open-ended) \\
\hline & 1. What is your academic background? Name your study programme(s) and your specialisation. \\
\hline \multirow[t]{6}{*}{$\begin{array}{l}\text { Academic and } \\
\text { educational } \\
\text { background }\end{array}$} & $\begin{array}{l}\text { 2. Did you learn about the added-value of stakeholder involvement in climate change or sustainability research } \\
\text { during your studies? a. If yes, what reasons for incorporating stakeholders were mentioned? Where there any } \\
\text { reasons mentioned for not employing participatory approaches? }\end{array}$ \\
\hline & $\begin{array}{l}\text { 3. Did you receive academic training on how to engage with stakeholders in participatory manner?. a. If yes, } \\
\text { which theories or approaches, methods or tools were mentioned?. b. If yes, and based on your research } \\
\text { experience, how could the academic training be improved? }\end{array}$ \\
\hline & $\begin{array}{l}\text { 4. Did you already work with stakeholders during your studies? If yes, please briefly describe what stakeholder } \\
\text { type and which way this was done. }\end{array}$ \\
\hline & 5. What is your current field of research? \\
\hline & $\begin{array}{l}\text { 6. Do you think that theoretical knowledge on stakeholder participation is important for working within your field? } \\
\text { If yes, give one example. }\end{array}$ \\
\hline & $\begin{array}{l}\text { 7. Do you think that practical experience in stakeholder participation is important for working within your field? If } \\
\text { yes, which topics or questions require stakeholder participation? }\end{array}$ \\
\hline \multirow{4}{*}{$\begin{array}{l}\text { Participatory } \\
\text { approaches and their } \\
\text { implementation }\end{array}$} & $\begin{array}{l}\text { 8. Do you actively involve stakeholders in your current and recent work? If yes, what kind of stakeholders are } \\
\text { involved? If no, proceed to question } 13 .\end{array}$ \\
\hline & 9. Which methods and tools do you use to involve stakeholders? (Please describe the methods or tools briefly) \\
\hline & $\begin{array}{l}\text { 10. Which levels of participation do you reach with stakeholders during your work most commonly? (Information, } \\
\text { Consultation, Involvement, Collaboration and Empowerment) }\end{array}$ \\
\hline & $\begin{array}{l}\text { 11. Which problems have you encountered when involving stakeholders in practice (conceptual difficulties, } \\
\text { management problems, convincing stakeholders to work with you...) and how did you solve them? }\end{array}$ \\
\hline \multirow{2}{*}{$\begin{array}{l}\text { Transdisciplinary } \\
\text { research and scientific } \\
\text { dissemination }\end{array}$} & $\begin{array}{l}\text { 12. In general, do you rather associate benefits or challenges with transdisciplinary research? What are the } \\
\text { main benefits and/or challenges? }\end{array}$ \\
\hline & $\begin{array}{l}\text { 13. Have you ever published a scientific paper that contains outcomes that were co-produced with stakeholders? } \\
\text { a. If yes, please describe what kind of results were obtained. b. How did you identify an appropriate journal? } \\
\text { Was it difficult to find one? }\end{array}$ \\
\hline
\end{tabular}


Table 2. Survey themes and items of the online ex-post survey.

\begin{tabular}{ll}
\hline Survey themes & Items (all open-ended) \\
\hline & $\begin{array}{l}\text { 1. What is the most significant insight you gained during the workshop for your current work? Please describe } \\
\text { briefly. }\end{array}$ \\
\cline { 2 - 2 } $\begin{array}{l}\text { Assumed learning } \\
\text { outcomes on personal } \\
\text { knowledge }\end{array}$ & $\begin{array}{l}\text { 2. Did you achieve new knowledge or did you update your knowledge of stakeholder involvement and } \\
\text { participatory approaches? Please describe the new achieved/updated topics briefly. }\end{array}$ \\
\cline { 2 - 2 } & 3. How will you make use of the insights that you have gained during the workshop? Please describe briefly. \\
\hline $\begin{array}{l}\text { Resolving some } \\
\text { stumbling-blocks related to } \\
\text { stakeholder engagement }\end{array}$ & $\begin{array}{l}\text { 4. What is the effect of the workshop in terms of resolving some of your own stumbling blocks within your } \\
\text { research? Please describe briefly. }\end{array}$ \\
\hline
\end{tabular}

\section{Results}

\subsection{Workshop Participants and Their Inter-and Transdisciplinary Education Levels}

The results show that most early career climate change and sustainability researchers attending the workshop had academic backgrounds in interdisciplinary fields. Most of them were trained in interdisciplinary bachelor's or master's programs, like environmental sciences, geography, natural resources management, ecological engineering or human and social ecology. Only two participants were trained in a more disciplinary field, namely economics. Since those fields traditionally are open for transdisciplinarity, every second workshop participant therefore knew about the potential added-value of including societal stakeholders in climate change and sustainability research before the workshop. Reasons for involving stakeholders into research practice that were picked up by workshop participants during their undergraduate education were manifold. For example, intense collaborations with stakeholders were argued to be effective for societal change and also justified since 'stakeholders could have the necessary knowledge for a given research question' or simply because 'climate change and sustainability research are dealing with real world problems and therefore many people of society are affected'. Moreover, the practice of inviting stakeholders into the research process could 'improve research due to a reality check', and 'it ensures that decisions in planning are O.K. for people'.

Workshop participants also argued to have learned about several reasons for not involving stakeholders in their research projects during their higher education. This is because 'stakeholder participation can also consume a lot of resources and may not lead to the wanted results', or because collaboration between scientists and societal stakeholders is believed to be 'time-consuming' and there is the risk that 'results may not be reproducible'.

The analysis of workshop participants' educational experiences also revealed that besides gaining generic insights into inter- and transdisciplinarity, they also received some more specific methodological training on how to engage with stakeholders before enrolling in a $\mathrm{PhD}$ program or accepting a post-doc position. Workshop participants either learned about participatory approaches like 'agentbased modelling' or 'wider transdisciplinary theories'. Other tools for stakeholder involvement and participatory research the participants had experience with were applying 'expert interviews', 'focus groups', 'role plays', 'scenario analysis', 'world-café', 'workshops' and even 'climate narratives'. Among workshop participants, there was consensus that especially 'qualitative methods' from the social sciences are particularly suitable for transdisciplinary research endeavours.

Some participants also reported that they have already collaborated with stakeholders during their bachelor's or master's programmes. For example, participants did research with 'visitors of Austrian National Parks', 'natural hazard managers', 'farmers', 'members of institutions, administration and municipalities', 'teenagers' and 'decisionmakers in the Austrian climate and energy sector'. Different levels of science-society interactions were reached inasmuch some workshop participants engaged with societal stakeholders during their bachelor's or master's for 'risk communication' or just 'polling'. Others involved stakeholders in 'design thinking processes' or 'participatory scenario analysis'.

\subsection{Workshop Participants' Practical Experiences when Working with Societal Stakeholders}

The analysis further showed that when becoming PhD students or post-docs the workshop participants continued to conduct inter-and transdisciplinary research. They are recently contributing to three main scientific fields: climate change research (i.e. focusing on management, communication/education and behaviour); flood risk research (i.e. focusing on management, communication and behaviour); and disaster risk reduction (i.e. focusing on vulnerability, communication, and management). Other fields were land-use dynamics (i.e. focusing on scenario building), sustainability science (i.e. focusing on the Anthropocene age), responsible research and innovation, de-growth studies and feminist methodologies.

Across all identified research fields, most workshop par- 
ticipants claimed that they would feel increasingly required to develop integrative skills as well as competencies in risk and science communication. They also argued that more knowledge on and methodological know-how for participatory settings could be useful to better navigate transdisciplinary research and its outcomes. Two statements reflect those perspectives:

Respondent A: 'I think it is good to know participatory toolboxes (methodological approaches), that one can relate to'. Respondent B: 'For researchers in climate change adaptation, it is crucial to know different theories whether stakeholders can contribute to a research problem, or not'.

Workshop participants also argued that working with stakeholders would require ongoing learning and that practical experience is highly valued by their institutions and teams. Two additional statements reflect their views:

Respondent C: 'Practical experience helps to understand and facilitate the process of working with people'. Respondent D: 'Stakeholder participation requires a lot of practice and is, to some, degree learning by doing. In my opinion, any research that tries to identify solutions to societal challenges should involve and attract stakeholders'.

The results on research experiences indicated that workshop participants reach different levels of engagement when working with stakeholders in their research projects. These phases of engagement are referred to as (1) information, (2) consultation, (3) collaboration and (4) empowerment [44]. Most participants claimed that, in their research projects, they usually inform, consult and collaborate with stakeholders under a common research goal. Just one participant claimed that stakeholders would be empowered through his or her research project. Even as deep engagement between researchers and stakeholders was perceived as highly important it was also recognised that 'empowerment is difficult to measure'.

Participatory tools used by workshop participants during their research projects before the workshop mainly referred to conventional project management tools and some qualitative research methods. For example, 'workshop settings' or 'role plays' were undertaken to establish collaboration, and 'design thinking' as well as 'serious games' were used for co-production of knowledge or policy options. Participants applied 'semi-structured interviews', 'surveys' and 'thematic mapping' in efforts to consult stakeholders. In terms of epistemological theories for communication with stakeholders, 'constructivism' was perceived as an effective approach or theory for participatory research endeavours.

The results of this category also show that even though most workshop participants have learned about inter-and transdisciplinarity during their undergraduate years they still face several stumbling blocks when conducting their postgraduate inter-and transdisciplinary climate change and sustainability research. A typical stumbling block was finding a common language with stakeholders for adequately transitioning scientific content to societal contexts. Establishing communication routines to express the societal relevance of inter- and transdisciplinary research outcomes was a reported stumbling block as well. Another issue was building trust between researchers and stakeholders. Two statements reflect this perspective:

Respondent E: 'Sometimes, it is hard to establish initial trust with stakeholders'. Respondent F: 'Translating research results into a language that is understandable to the public is a challenge itself. Despite uncertainties in scientific results, decision-makers need clear messages for their decisions'.

As a second category of stumbling-blocks reported by workshop participants deals with project management and grant writing. Two statements are given below:

Respondent G: 'Identifying dates and arranging meetings with stakeholders - almost 24/7 project management'. Respondent H: 'For a research proposal, I failed to describe exchange between stakeholders and researchers robustly enough'.

The workshop participants recognised several benefits of inter- and transdisciplinary research for their current research projects, for example 'triggering mutual learning among academic and non-academic actors', 'creating acceptance of research-led solutions' and 'overcoming a reductionist view' of narrowly focused research attempts. Nevertheless, they also were concerned with some other challenges related to the analysis and dissemination of transdisciplinary processes, like 'finding adequate transdisciplinary journals' and 'arguing for a certain participatory method or theory in front of senior colleagues'. Problems like 'testing the effectiveness of transdisciplinary research by intersubjective means' and 'gaining the acceptance from non-transdisciplinary colleagues' were reported as well.

\subsection{Workshop Participants' self-reported Learning Outcomes}

After participating in the early career workshop, some workshop participants indicated that they have gained new knowledge related to participatory approaches and argued to have deepened their understanding of collaboration with societal stakeholders. More specifically, workshop participants claimed to have learned about new methods to engage with different types of stakeholders, and were becoming more aware of which factors could limit a transdisciplinary research design. One statement is given below:

Respondent I: 'I gained the insight that there is a broad range of different tools to involve stakeholders within studies. I also gained the insight that prior to the selection of stakeholders, an analysis should be conducted to better know your audience and the types of benefits that stakeholders can bring into research projects. I learned that the process from stakeholder identification to involvement towards coproduction of research outcomes should be organized as systematically and rigor as possible'.

For many participants, the workshop represented a first opportunity to jointly discuss the challenges related to stakeholder involvement in their research projects, however it was also mentioned that a workshop never can replace learning 
from personally practising research. One such statement is given below:

Respondent J: 'The workshop showed that there are some common mistakes in implementing participatory processes. The best way to learn and resolve stumbling blocks, however, is through hands-on, practical experience'.

The workshop was also reported to have been effective in motivating participants to apply participatory research approaches in the future. At the same time, it was reported that a more profound understanding of the different levels of engagement with stakeholders is acquired to really lead to transformational change for sustainability in wider society. Three reflective statements from workshop participants are as follows:

Respondent K: 'This survey is a good way to reflect about the workshop. The workshop helped me to be more explicit about aims and methods in stakeholder involvement, and I will look more deeply in different case studies on participatory approaches'. Respondent L: 'I will respect new insights that I gained during the workshop in my PhD thesis. I also think that these insights will help me writing proposals dealing with stakeholder involvement'. Respondent M: 'I am more careful to reflect whether I should integrate stakeholders within my project or not. This should be done to avoid stakeholder fatigue and it should be critically evaluated whether participation with stakeholders creates added value or not'.

Despite workshop participants reported to have experienced learning outcomes due to the workshop, it is important to note that some participants claimed that it did not resolve all stumbling blocks or confusions related to collaboration with stakeholders or inter- and transdisciplinary climate change and sustainability research. One statement is as follows:

Respondent N: 'I will try harder in current and future research to really co-design projects, from the beginning till the end. My stumbling block in terms of how to evaluate the effectiveness of participatory research methods was not completely resolved, but I got some ideas how to do it'.

\subsection{Workshop Participants' Recommendations to Improve Higher Education on Transdisciplinary Research in Austria}

During the workshop, workshop participants reflected upon how to improve current inter- and transdisciplinary university education, respectively how to improve participatory research training for stakeholder involvement in Austria. They came up with several transformative suggestions that are relevant to several bachelor's and master's programmes at Austrian universities. The identified recommendations are as follows:

- Lectures on participatory approaches should provide university students in the fields of climate change and sustainability sciences with 'basic introductions to qualitative research, theories in social sciences and stakeholder engagement'.

- Excursions in which university students could 'develop and train participatory methods together with stakeholders and fellow students'.

- Hands-on courses in which 'one can design and implement participatory tools by his or her own' and 'indepth workshops' on stakeholder involvement, both embedded in existing university curricula, should 'offer an extensive overview of possible tools and methods'.

- Inter-and transdisciplinary mini-projects on stakeholder involvement should be offered in higher education already 'during undergraduate years' since 'experience beats everything'.

- Toolkits on 'how to work with stakeholders' should be discussed and employed during university courses and in 'lecture notes'.

It was further tried to embed the potential improvements recommended by workshop participants into a larger context using the approach from Killion et al. [31] (see Figure 2). Like them we plotted each single measure against its assumed implementation effort to inform department leaders, deans of studies, lectures, and other scientific professionals who are usually responsible for developing higher education. We also evaluated whether each measure could be aligned with existing science curricular in the Austrian university system or not. The results of this reflective process suggest that all measures could be theoretically applied, but would have different outcomes to learners. For example, it should be possible for study committees and lectures to develop and integrate thematic lectures on inter-and transdisciplinarity into existing bachelor's and master's programmes that set out to prepare students for solving climate change and sustainability issues. Such conceptual lectures could be used to elaborate on social science theories on communication and/or science-society collaborations as well to introduce technical toolkits showcasing frameworks and methods and its specific advantages and disadvantages for participatory research with stakeholders. Workshop participants however claimed that transdisciplinarity must also be personally experienced and therefore they recommended that coming generations of climate change and sustainability researchers in Austria could benefit from authentic learning in excursions, hands-on courses and mini-projects with stakeholders during their undergraduate education. It is further believed that an improved transdisciplinary education not only could lead to scientific excellence in the long-term but could also reduce trivial but often experienced stumbling-blocks when collaborating with societal stakeholders. Referring to practical stumbling-blocks, workshop participants reflected on each measure's potential for preparing early career researchers for more successful inter-and transdisciplinary grant-writing, sound project management and more flexible communication skills. The latter is important for translating inter-and transdisciplinary research into real-life management contexts. 


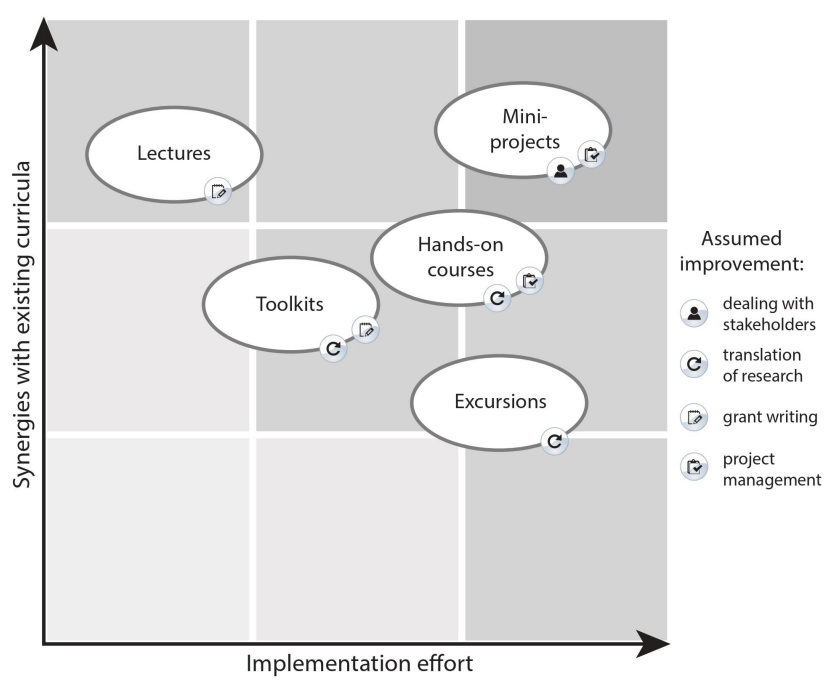

Figure 2. Early career climate change and sustainability researchers' recommendations for improving university education in Austria specifically regarding collaboration with stakeholders using the approach from Killion et al. [31].

\section{Discussion}

This paper set out to qualitatively examine twelve early career climate change and sustainability researchers' (and young professionals') educational and practical experiences in conducting participatory research with stakeholders in the context of Austria. Thematic coding of survey data and documented workshop reflections showed that participants had received undergraduate education on inter-and transdisciplinarity and had practical experiences before choosing to work with stakeholders in their recent $\mathrm{PhD} /$ post-doc projects. Nevertheless, several stumbling-blocks are found to complicate their every-day collaboration with stakeholders and the workshop was perceived as a good opportunity to engage in peer discussion and practice self-reflexivity. Reflections during the workshop resulted in several recommendations for alternative learning concepts to improve current inter-and transdisciplinary education at Austrian universities.

\subsection{Comparing Survey Results with Findings of Similar Studies}

Results of this study confirm previous research insights derived from examining other contexts than Austria. For example, findings from Haider et al., who surveyed 325 early career sustainability scientists in the broader network of resilience research and practice during the Resilience 2014 conference in Montpelier, France, also apply to early career climate change and sustainability researchers in Austria: (a) workshop participants mainly were trained in interdisciplinary bachelor's or master's programmes and (b) participants' practical experiences with stakeholders underline that 'methodological groundedness' (i.e. the ability of a researcher to understand and put a certain transdisciplinary method into practice) as well as 'epistemic agility' (i.e. the ability of a researcher to understand claims about through and knowledge outside academia) are understood as key guiding principles for successful participatory research with stakeholders ([27], p. 197).

Our results also agree with Killion et al. [31] inasmuch workshop participants reported that low levels of teamscience skills and inappropriate project management are likely to raise practical difficulties for doctoral students during stakeholder involvement. Like Killion et al. [31] we conclude that as more collaboration with stakeholders is expected by decision-makers, funders or senior colleagues, the more care must be given to systematically prepare pre-doc and post-doc researchers for establishing robust transdisciplinary platforms $[45,46]$. This means that science networks in Austria and other countries are recommended to provide sufficient institutional support for developing the next generation of inter- and transdisciplinary researchers. This should be undertaken not only through increased levels of funding [47], but also by offering continuous learning opportunities that equip the next generation of scholars with a deep understanding of agency-based approaches and public engagement [48].

Going beyond the existing literature by assessing the workshop participants' previous undergraduate education experiences, our results show that most workshop participants were knowledgeable about state-of-the-art methods in participatory research, like world-cafés or stakeholder discussions in focus groups, already prior to their $\mathrm{PhD}$ or post-doc projects. Some even reported to use facilitation tools like design thinking in their current research activities. None of the workshop participants however indicated to have prior knowledge or practical experience with methods for real-life transdisciplinary experimentation, like real-world laboratories [49], the future search conference method or other tools relevant for facilitating sustainable outcomes among stakeholder groups. Methodological guidance can be found in the toolkit compendium of the scientific journal GAIA-Ecological Perspectives for Science and Society [50]. We think that limited awareness of tools useful to transdisciplinary experimentation is problematic because it implies that ways to effective knowledge integration, which is the process by which transdisciplinary research combines scientific outcomes and non-academic knowledge to trigger real-life solutions [51], are unknown to young climate change and sustainability researchers. A weak understanding of strategies to re-integrate outcomes of transdisciplinary research into societal practice [20] could also explain why most participants were sceptical whether their $\mathrm{PhD}$ or post-doc research is effective in empowering stakeholders for sustainability. 


\subsection{Improving Inter- and Transdisciplinary University Education in Austria}

One of the most important findings of this case-study is that interdisciplinary bachelor's or master's programs in Austria do not necessarily prepare early career climate change and sustainability researchers with the conceptual knowledge as well as management skills for stakeholder involvement. Degrees in environmental sciences or human and social ecology may prepare students for taking more holistic approaches to problem solving and may strengthen their systems thinking skills [52]. It is however argued that this is not enough for solving challenges in transdisciplinary research, like dealing with different epistemological realities, being flexible in co-production of knowledge or gaining higher levels of self-reflexivity for critically evaluating one owns transdisciplinary research [21]. Most workshop participants have directly entered the inter-and transdisciplinary arena after their graduation. Participatory research trainings sporadically taken during the first and second years of the $\mathrm{PhD}$ therefore might not be the only optimal strategy to foster early career researchers' participatory research competences, especially if average time of institutional employment during $\mathrm{PhD}$ stage in Austria is limited to three years. Hence it is proposed that new and innovative pedagogic strategies applied already during bachelor's or master's programmes could be a promising educational investment for sustainable development in Austria; these might include several of our workshop participants' recommendations, like offering interand transdisciplinary mini-projects or hands-on courses. In such learning activities, learners should be allowed to freely experiment with participatory approaches, and such undergraduate teachings may also make a meaningful contribution to the above-mentioned science plan [39].

Involving societal stakeholders into such transdisciplinary learning activities is central, however benefits must be offered by Universities to keep societal actors engaged over longer periods of time. We suggest, for example, providing stakeholders free access to scientific journals as well as highlighting throughout the process the practical relevance of co-produced research results for the stakeholders' fields of activity. Mainstreaming transdisciplinarity into the academic system is central [53] and this also was discussed during the early career workshop.

Transdisciplinary lectures in current science curricula therefore could be used to make undergraduate students more familiar with widely accepted stakeholder frameworks $[54,55]$, and toolkits for managing participatory research processes. Toolkits like the ones of Welp et al. [22] or Wittmayer and Hölscher [56] could become common knowledge for upcoming inter-and transdisciplinary climate change and sustainability researchers. Overall, our suggestions for improving higher education in Austria were found to be very well in line with Wittmayer and Schäpke [57], who argued that transdisciplinary cooperation should already be part of education programs to enable young researchers to deal with the challenges ahead.

\subsection{Mutual Learning Effects among Early Career Researchers and Implications of the Workshop}

Interestingly, the workshop not only was reported to be effective in providing new knowledge but also to foster peergroup discussion. It also seemed to have strengthened early career researchers' critical thinking about inter-and transdisciplinarity. Several reference examples support this claim. Mutual learning between workshop participants also included discussions between those researchers who published a transdisciplinary paper before and others who were interested to do so. These workshops therefore can be a place in sharing knowledge on, and publishing experiences in, the steadily emerging peer-reviewed academic journals that do foster transdisciplinary research, for example Ecology and Society, GAIA, One Earth, Sustainability Science, Ambio and others [58]. What must be critically admitted however is that the workshop design characterized by a short initial lecture given by a senior researcher and the strong emphasis on group reflections was not fully effective in resolving workshop participants' methodological stumblingblocks with stakeholder involvement. For better methodical training a more interactive workshop design therefore must be chosen in which methods are tested and/or in which not only senior researcher but also stakeholders could be invited. Ideally, such stakeholders should have collaborated in transdisciplinary projects before and should be willing to share their lessons learned. Despite this limitation, the workshop indicates that there is a largely unexploited interest among early career climate change and sustainability researchers in Austria to reach rigorousness in participatory research with societal stakeholders. Since this interest fits well into the scope of the above-mentioned science plan (see background chapter), the CCCA and similar national science consortia are encouraged to build on this common interest by promoting and holding early career workshops on a regular basis. Furthermore, they are encouraged to develop their own forms of innovative training for inter-and transdisciplinary research [39]. Examples of mutual learning opportunities that are also relevant to the Austrian context are the Postdoc Academy for Transformational Leadership [59], the td Academy [60] or the TD summer school from the Leuphana University, Germany [61].

\subsection{Study Limitations and Further Research Needs}

Several limitations of this study are acknowledged. Firstly, the study's sample size $(\mathrm{N}=12)$ is small and therefore we avoid a generalization of our results beyond the national context of Austria. This country approach to generalization is in line with similar studies also focussing on early career challenges related to transdisciplinary sustainability research, for example Killion et al. [31] ( $\mathrm{N}=26$, United States of America) or Jaeger-Erben et al. [28] ( $N=12$, Germany). Small sample sizes per se are not problematic to single-case study research inasmuch they can be instructive to complex social phenomena $[42,62]$. However, 
we also understand that our results and recommendations should be interpreted with caution inasmuch they are not fully representative of all early career climate change and sustainability scientists in Austria. We therefore encourage other scholars to scale up our workshop approach and to invite a larger number of early career researchers to such events. But at the same time, we also note that such future research could learn from our qualitative insights since they have pilot-study character. The second limitation relates to the selection of workshop participants. Since participants had to apply for the workshop, the sample of course does not account for other PhD or post-doc researchers in the fields of climate change and sustainability who probably were not interested, had not time to join the event or simply were not informed about the workshop. Furthermore, the qualitative analysis of the workshop's effectiveness only is based on workshop participants' self-assessment. Selfreported learning of course is subjective and future works are therefore recommended to explore whether participants had tested strategies from the reflective workshop in their early career research practice more objectively.

\section{Conclusions}

This case study has provided in-depth insight into Austrian early career climate change and sustainability researchers' educational and practical experiences when working with societal stakeholders in their inter- and transdisciplinary $\mathrm{PhD}$ or post-doc projects. Results confirm those of previ-

\section{References and Notes}

[1] Chin A, Beach T, Luzzadder-Beach S, Solecki WD. Challenges of the "Anthropocene". Anthropocene. 2017;20:1-3. doi:10.1016/j.ancene.2017.12.001.

[2] Steffen W, Rockström J, Richardson K, Lenton TM, Folke C, Liverman $D$, et al. Trajectories of the Earth System in the Anthropocene. Proceedings of the National Academy of Sciences. 2018;115(33):82528259. doi:10.1073/pnas.1810141115.

[3] Global Warming of $1.5^{\circ} \mathrm{C}$. An IPCC Special Report on the impacts of global warming of $1.5^{\circ} \mathrm{C}$ above pre-industrial levels and related global greenhouse gas emission pathways, in the context of strengthening the global response to the threat of climate change, sustainable development, and efforts to eradicate poverty. In: Masson-Delmotte V, Zhai P, Pörtner HO, Roberts D, Skea J, Shukla P, et al., editors. Intergovernmental Panel on Climate Change: Summary for policymakers; 2018. Available from: https://www.ipcc.ch/site/assets/uploads/sites/2/ 2019/05/SR15_SPM_version_report_LR.pdf.

[4] Hansen G, Stone D. Assessing the Observed Impact of Anthropogenic Climate Change. Nature Climate Change. 2015;6(5):532537. doi:10.1038/nclimate2896.

[5] Lebreton L, Slat B, Ferrari F, Saint-Rose B, Aitken J, Marthouse $R$, et al. Evidence that the Great Pacific Garbage Patch is Rapidly Accumulating Plastic. Scientific Reports. 2018;8(4666). doi:10.1038/s41598-018-22939-2.

[6] Tesfaw AT, Pfaff A, Golden Kroner RE, Qin S, Medeiros R, B Mascia M. Land-use and Land-cover Change Shape the Sustainability and Impacts of Protected Areas. Proceedings of the National Academy of Sciences. 2018;115(9):2084-2089. doi:10.1073/pnas.1716462115.

[7] Olsson P, Moore ML, Westley FR, McCarthy DDP. The Concept of the Anthropocene as a Game-changer: A New Context for Social In- ous international studies on early career researchers and suggest that mutual learning among peers and senior researchers about stakeholder involvement, e.g. in the form of focused workshops, can have several positive effects. Workshop participants expand their knowledge, reflect more critically about transdisciplinary research designs, and simply can build a professional network. In addition, we find that graduate research training should not be perceived as the only strategy to resolve conceptual and practical stumblingblocks related to participatory research with societal stakeholders. One of our main conclusions is that early career researchers would benefit substantially if their preceding bachelor's and master's programmes in the fields of climate change and sustainability sciences would incorporate more practice-oriented transdisciplinary learning activities. This includes, amongst others, more elaborate teaching techniques on how to re-integrate transdisciplinary research outcomes back into society.

\section{Acknowledgments}

The authors sincerely acknowledge the valuable and profound comments by two anonymous referees. We acknowledge the financial support of the Climate Change Center Austria (CCCA) and thank all workshop participants for also taking part in our accompanying study. Thomas Schinko was partly supported by funding from the Austrian Federal Ministry of Education, Science and Research, research project makingAchange. novation and Transformations to Sustainability. Ecology and Society. 2017;22(2). doi:10.5751/es-09310-220231.

[8] The Sustainable Development Goals Report 2018. United Nations; 2018. Available from: https://unstats.un.org/sdgs/files/report/2018/ TheSustainableDevelopmentGoalsReport2018-EN.pdf.

[9] Sendai Framework for Disaster Risk Reduction 2015-2030. Available from: https://www.undrr.org/publication/sendai-framework-disasterrisk-reduction-2015-2030.

[10] Paris Agreement; 2020. Available from: https://unfccc.int/sites/ default/files/english_paris_agreement.pdf.

[11] Knutti R. Closing the Knowledge-Action Gap in Climate Change. One Earth. 2019;1(1):21-23. doi:10.1016/j.oneear.2019.09.001.

[12] Reid WV, Chen D, Goldfarb L, Hackmann H, Lee YT, Mokhele K, et al. Earth System Science for Global Sustainability: Grand Challenges. Science. 2010;330(6006):916-917. doi:10.1126/science.1196263.

[13] Brondizio ES, O'Brien K, Bai X, Biermann F, Steffen W, Berkhout $\mathrm{F}$, et al. Re-conceptualizing the Anthropocene: A Call for Collaboration. Global Environmental Change. 2016;39:318-327. doi:10.1016/j.gloenvcha.2016.02.006.

[14] Kates RW. ENVIRONMENT AND DEVELOPMENT: Sustainability Science. Science. 2001;292(5517):641-642. doi:10.1126/science.1059386.

[15] Cornell S, Berkhout F, Tuinstra W, Tàbara JD, Jäger J, Chabay I, et al. Opening up Knowledge Systems for Better Responses to Global Environmental Change. Environmental Science \& Policy. 2013;28:60-70. doi:10.1016/j.envsci.2012.11.008.

[16] Naustdalslid J. Climate Change - the Challenge of Translating Scientific Knowledge into Action. International Journal of Sustainable Development \& World Ecology. 2011;18(3):243-252. doi:10.1080/13504509.2011.572303.

[17] Hackmann H, Moser SC, Lera St Clair A. The Social Heart of Global Environmental Change. Nature Climate Change. 2014;4(8):653-655 
doi:10.1038/nclimate2320.

[18] Seidl R, Simon Brand F, Stauffacher M, Krütli P, Bao Le Q, Spörri A, et al. Science with Society in the Anthropocene. AMBIO. 2013;42(1):5-12. doi:10.1007/s13280-012-0363-5.

[19] Abson DJ, Fischer J, Leventon J, Newig J, Schomerus T, Vilsmaier $\mathrm{U}$, et al. Leverage Points for Sustainability Transformation. Ambio. 2016;46(1):30-39. doi:10.1007/s13280-016-0800-y.

[20] Lang DJ, Wiek A, Bergmann M, Stauffacher M, Martens P, Moll P, et al. Transdisciplinary Research in Sustainability Science: Practice, Principles, and Challenges. Sustainability Science. 2012;7(S1):2543. doi:10.1007/s11625-011-0149-x.

[21] Fazey I, Schäpke N, Caniglia G, Patterson J, Hultman J, van Mierlo B, et al. Ten Essentials for Action-oriented and Second Order Energy Transitions, transformations and climate change research. Energy Research \& Social Science. 2018;40:54-70. doi:10.1016/j.erss.2017.11.026

[22] Welp $M$, de la Vega-Leinert A, Stoll-Kleemann S, Jaeger CC. Science-based Stakeholder Dialogues: Theories and Tools. Global Environmental Change. 2006;16(2):170-181. doi:10.1016/j.gloenvcha.2005.12.002.

[23] Gregory R, Keeney RL. A Practical Approach to Address Uncertainty in Stakeholder Deliberations. Risk Analysis. 2017;37(3):487-501. doi:10.1111/risa.12638.

[24] Briley L, Brown D, Kalafatis SE. Overcoming Barriers During the Co-production of Climate Information for Decision-making. Climate Risk Management. 2015;9:41-49. doi:10.1016/j.crm.2015.04.004.

[25] Walter Al, Helgenberger S, Wiek A, Scholz RW. Measuring Societal Effects of Transdisciplinary Research Projects: Design and Application of an Evaluation Method. Evaluation and Program Planning. 2007;30(4):325-338. doi:10.1016/j.evalprogplan.2007.08.002.

[26] Mauser W, Klepper G, Rice M, Schmalzbauer BS, Hackmann $H$, Leemans $R$, et al. Transdisciplinary Global Change Research: The Co-creation of Knowledge for Sustainability. Current Opinion in Environmental Sustainability. 2013;5(3-4):420-431. doi:10.1016/j.cosust.2013.07.001.

[27] Haider LJ, Hentati-Sundberg J, Giusti M, Goodness J, Hamann M, Masterson VA, et al. The Undisciplinary Journey: Early-career Perspectives in Sustainability Science. Sustainability Science. 2017;13(1):191-204. doi:10.1007/s11625-017-0445-1.

[28] Jaeger-Erben M, Kramm J, Sonnberger M, Völker C, Albert C, Graf A, et al. Building Capacities for Transdisciplinary Research: Challenges and Recommendations for Early-Career Researchers. GAIA - Ecological Perspectives for Science and Society. 2018;27(4):379-386. doi:10.14512/gaia.27.4.10.

[29] Maher B, Sureda Anfres M. Young Scientists Under Pressure: What the Data Show. Nature. 2016;538(7626):444-444. doi: $10.1038 / 538444 a$

[30] Klenk NL, Meehan K, Lee Pinel S, Mendez F, Torres Lima P, Kammen DM. Stakeholders in Climate Science: Beyond Lip Service? Science. 2015;350(6262):743-744. doi:10.1126/science.aab1495.

[31] Killion A, Sterle K, Bondank E, Drabik J, Bera A, Alian S, et al. Preparing the Next Generation of Sustainability Scientists. Ecology and Society. 2018;23. doi:10.5751/ES-10395-230439.

[32] Kueffer C, Hirsch Hadorn G, Bammer G, van Kerkhoff L, Pohl C. Towards a Publication Culture in Transdisciplinary Research. GAIA Ecological Perspectives for Science and Society. 2007;16(1):22-26. doi:10.14512/gaia.16.1.8

[33] Hein CJ, Ten Hoeve JE, Gopalakrishnan S, Livneh B, Adams HD, Marino EK, et al. Overcoming Early Career Barriers to Interdisciplinary Climate Change Research. Wiley Interdisciplinary Reviews: Climate Change. 2018;9(5):e530. doi:10.1002/wcc.530.

[34] Moore M, Martinson ML, Nurius PS, Kemp SP. Transdisciplinarity in Research: Perspectives of Early Career Faculty. Research on Social Work Practice. 2017;28(3):254-264. doi: $10.1177 / 1049731517708033$.

[35] Rivera-Ferre M, Pereira L, Karpouzoglou T, Nicholas K, Onzere S, Waterlander W, et al. A Vision for Transdisciplinarity in Future Earth: Perspectives from Young Researchers. Journal of Agriculture, Food Systems, and Community Development. 2013;pp. 249-260. doi:10.5304/jafscd.2013.034.031.

[36] Schinko T, Borgomeo E, Dufva M, Figge L, Schipfer F. Re-shaping Sustainability Science for the $21^{\text {st }}$ Century: Young Scientists' Per- spectives. Laxenburg, Austria: International Institute for Applied Systems Analysis; 2017. Working Paper WP-17-001. Available from: http://pure.iiasa.ac.at/id/eprint/14375/.

[37] Hanson C, Palutikof J, Dlugolecki A, Giannakopoulos C. Bridg ing the Gap Between Science and the Stakeholder: The Case of Climate Change Research. Climate Research. 2006;31:121-133. doi:10.3354/cr031121.

[38] Moore J. Seven Recommendations for Creating Sustainability Education at the University Level. International Journal of Sustainability in Higher Education. 2005;6(4):326-339. doi:10.1108/14676370510623829.

[39] Science Plan - On the Strategic Development of Climate Research in Austria. Wien, Austria: Climate Change Centre Austria; 2018. Available from: https://ccca.ac.at/fileadmin/ 00_DokumenteHauptmenue/03_Aktivitaeten/Science_Plan/ CCCA_Science_Plan_Englisch_2018111.pdf.

[40] Preston BL, Rickards L, Fünfgeld H, Keenan RJ. Toward Reflexive Climate Adaptation Research. Current Opinion in Environmental Sustainability. 2015;14:127-135. doi:10.1016/j.cosust.2015.05.002.

[41] Clutterbuck D. Talking Business: Making Communication Work. Routledge; 2012. doi:10.4324/9780080518428.

[42] Flyvbjerg B. Five Misunderstandings About Case-Study Research. Qualitative Inquiry. 2006;12(2):219-245. doi:10.1177/1077800405284363.

[43] Bengtsson M. How to Plan and Perform a Qualitative Study Using Content Analysis. NursingPlus Open. 2016;2:8-14. doi:10.1016/j.npls.2016.01.001.

[44] Policy Brief on Stakeholder Engagement Published. ERA-LEARN Available from: https://www.era-learn.eu/news-events/news/policybrief-on-stakeholder-engagement-published.

[45] Schneider F, Buser T. Promising Degrees of Stakeholder Interaction in Research for Sustainable Development. Sustainability Science. 2017;13(1):129-142. doi:10.1007/s11625-017-0507-4.

[46] Herweg K, Schäfer N, Zimmermann A. Guidelines for Integrative Training in Inter- and Transdisciplinary Research Settings. Hints and Tools for Trainers of Trainers; 2012.

[47] Vasbinder JW, Andersson B, W BA, Boasson M, de Boer R, Changeux JP, et al. Transdisciplinary EU Science Institute Needs Funds Urgently. Nature. 2010;463(7283):876-876. doi:10.1038/463876a.

[48] Reed MS, Vella S, Challies E, de Vente J, Frewer L, HohenwallnerRies D, et al. A Theory of Participation: What Makes Stakeholder and Public Engagement in Environmental Management Work? Restoration Ecology. 2017;26:S7-S17. doi:10.1111/rec.12541.

[49] Bernert P, Haaser A, Kühl L, Schaal T. Towards a Real-world Laboratory: A Transdisciplinary Case Study from Lüneburg. GAIA Ecological Perspectives for Science and Society. 2016;25(4):253259. doi:10.14512/gaia.25.4.7.

[50] Bammer G. Toolkits for Transdisciplinarity. Available from: https:// www.oekom.de/_uploads_media/files/gaia_flyer_toolkits_032911.pdf.

[51] Hoffmann S, Pohl C, Hering JG. Methods and Procedures of Transdisciplinary Knowledge Integration: Empirical Insights from four Thematic Synthesis Processes. Ecology and Society. 2017;22(1). doi:10.5751/es-08955-220127.

[52] McCright AM, Brian O'Shea W, Sweeder RD, Urquhart GR, Zeleke A. Promoting Interdisciplinarity through Climate Change Education. Nature Climate Change. 2013;3(8):713-716. doi:10.1038/nclimate1844

[53] Jahn T, Bergmann M, Keil F. Transdisciplinarity: Between Mainstreaming and Marginalization. Ecological Economics. 2012;79:1-10. doi:10.1016/j.ecolecon.2012.04.017.

[54] Luyet V, Schlaepfer R, Parlange MB, Buttler A. A Framework to Implement Stakeholder Participation in Environmental Projects. Journal of Environmental Management. 2012;111:213219. doi:10.1016/j.jenvman.2012.06.026.

[55] Polk M. Transdisciplinary co-production: Designing and Testing a Transdisciplinary Research Framework for Societal Problem Solving Futures. 2015;65:110-122. doi:10.1016/j.futures.2014.11.001.

[56] Wittmayer J, Hölscher K. Transformationsforschung: Definitionen Ansätze Methoden. Dessau-Roßlau; 2018. doi:10.1111/rec.12541.

[57] Wittmayer JM, Schäpke N. Action, Research and Participation: Roles of Researchers in Sustainability Transitions. Sustainability Science. 2014;9(4):483-496. doi:10.1007/s11625-014-0258-4. 
[58] Felt U, Igelsböck J, Schikowitz A, Völker T. Growing into What? The (un-)disciplined Socialisation of Early Stage Researchers in Transdisciplinary Research. Higher Education. 2012;65(4):511-524. doi:10.1007/s10734-012-9560-1.

[59] Postdoc Academy for Transformational Leadership. Stuttgart, Germany: Robert Bosch Stiftung; 2020. Available from: https://www.bosch-stiftung.de/de/projekt/postdoc-academytransformational-leadership.

[60] tdAcademy-Plattform für transdisziplinäre Forschung und Stu- dien. Frankfurt am Main, Germany: Institut für sozial-ökologische Forschung (ISOE) gGmbH; 2020. Available from: https://tdacademy.de.

[61] TD Summer School. Available from: https://www.leuphana.de/ zentren/methodenzentrum/td-training.html.

[62] Roland Boddy C. Sample Size for Qualitative Research. Qualitative Market Research: An International Journal. 2016;19(4):426-432. doi:10.1108/qmr-06-2016-0053. 